\title{
A Three-Dimensional Strain Rosette Sensor Based on Graphene Composite with Piezoresistive Effect
}

\author{
Zhiqiang Wu $\mathbb{D}^{1}{ }^{1}$ Jun Wei, ${ }^{1}$ Rongzhen Dong, ${ }^{1}$ and Hao Chen ${ }^{2}$ \\ ${ }^{1}$ School of Civil Engineering, Central South University, Changsha 410075, China \\ ${ }^{2}$ China Construction Second Engineering Bureau Co. Ltd, Beijing 100071, China \\ Correspondence should be addressed to Zhiqiang Wu; 124801026@csu.edu.cn
}

Received 7 June 2019; Revised 24 September 2019; Accepted 10 October 2019; Published 22 November 2019

Academic Editor: Ching-Tai Ng

Copyright (C) 2019 Zhiqiang Wu et al. This is an open access article distributed under the Creative Commons Attribution License, which permits unrestricted use, distribution, and reproduction in any medium, provided the original work is properly cited.

\begin{abstract}
Obtaining the internal stress and strain state of concrete to evaluate the safety and reliability of structures is the important purpose of concrete structural health monitoring. In this paper, a three-dimensional (3D) strain rosette sensor was designed and fabricated using graphene-based piezoresistive composite to measure the strains in concrete structures. The piezoresistive composite was prepared using reduced graphene oxide (RGO) as conductive filler, cellulose nanofiber (CNF) as dispersant and structural skeleton, and waterborne epoxy (WEP) as polymer matrix. The mechanical, electrical, and electromechanical properties of RGO-CNF/WEP composite were tested. The results show that the tensile strength, elastic modulus, and conductivity of the composite are greatly improved by the addition of RGO and CNF. The relative resistance change of composite films demonstrates high sensitivity to mechanical strain with gauge factors of $16-52$. Within $4 \%$ strain, the piezoresistive properties of composites are stable with good linearity and repeatability. The sensing performance of the 3D strain rosette was tested. The measured strains are close to the actual strains of measure point in concrete, and the error is small. The RGO-CNF/WEP composite has excellent mechanical and piezoresistive properties, which enable the $3 \mathrm{D}$ strain rosette to be used as embedded sensor to measure the internal strain of concrete structures accurately.
\end{abstract}

\section{Introduction}

Concrete is the most widely used material in civil engineering. The service periods of concrete structures are usually several decades or even longer. In the long-term process, combined actions of multiple factors, such as load effect, environmental erosion, and material aging, will lead to damage accumulation and resistance attenuation of concrete structures $[1,2]$. If the crisis situation cannot be timely warned and repaired, it will easily lead to catastrophic accidents. Therefore, structural health monitoring is necessary to determine the stress and strain states of key points in concrete and to evaluate the safety and reliability of the structure.

Sensing system is the base of concrete structural health monitoring. Traditional sensors include strain gauges, fiber Bragg grating [3, 4], and piezoelectric materials [5-7]. However, these sensors have some problems, such as single testing direction, high cost, bad durability, and poor compatibility with concrete. The emergence of cement-based smart composites [8-14] provides a new sensing mean for structural health monitoring, and it has been well applied in civil engineering as embedded sensors. However, although the cement-based smart sensor has high sensitivity, good linearity, and well compatibility with concrete, it is greatly affected by environmental factors, especially temperature and humidity, and has poor plasticity. Therefore, it is mostly used to measure one-dimensional stress and strain in concrete. Polymer-based intelligent sensor $[15,16]$ can avoid the above problems, because of the good corrosion resistance and waterproofing, simple molding, and well plasticity of polymer materials.

Due to the unique crystal structures and properties, nanomaterials can be used to enhance and modify polymer, which provides a theoretical basis for the preparation of new sensors [17-20]. At present, most polymer-based intelligent composites are based on flexible materials such as rubber. Because of the low elastic modulus of rubber, the mechanical properties of concrete will be greatly reduced 

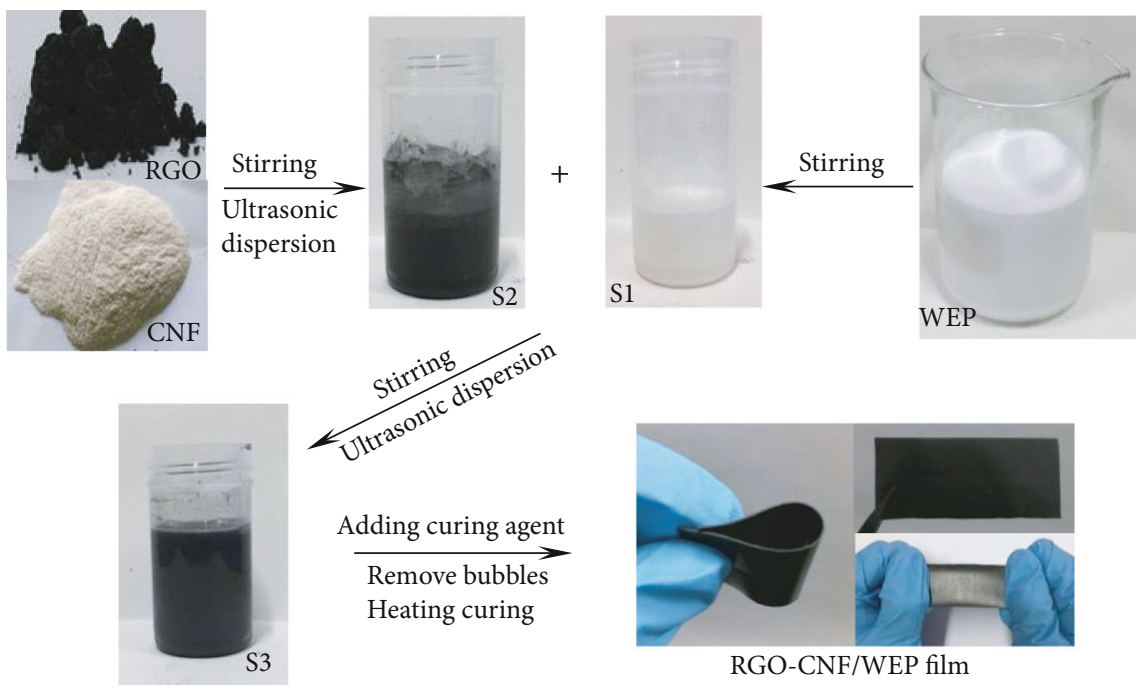

FIGURE 1: The fabrication process of the RGO-CNF/WEP composite.

when embedded in the component. In addition, the composites using nanocarbon black or carbon nanotube as conductive fillers have low sensitivity, high filling content, and poor repeatability. Therefore, to make new sensors, epoxy resin with high mechanical strength [21] is used as the matrix material, and graphene, a two-dimensional nanomaterial, with excellent mechanical and electrical properties [22] is selected as the conductive filler.

In this paper, a graphene-based composite material with piezoresistive effect was prepared first. RGO was used as the conductive filler of the composite. CNF with good dispersion in water [23] was used as dispersant and carries RGO to evenly disperse in WEP to form a stable and continuous $3 \mathrm{D}$ reinforcing and conductive network. The mechanical, electrical, and electromechanical properties of the composite were tested. Then, based on the strain theory, a 3D strain rosette was designed and fabricated to obtain the strain state of a point inside the concrete structure. The sensing elements of the strain rosette are six one-dimensional strain sensors formed by the RGO-CNF/WEP composite and arranged in six directions of an epoxy cube. At last, the sensing performance of the $3 \mathrm{D}$ strain rosette was tested and analyzed.

\section{Fabrication of the RGO-CNF/WEP Composite}

2.1. Materials and Instruments. Reduced graphene oxide (RGO) was purchased from Suzhou Tanfeng Graphene Technology Co., Ltd, China (purity $>98 \mathrm{wt} \%$, thickness 1-3 nm, flake size 0.5-5 $\mu \mathrm{m}$ ). Cellulose nanofiber (CNF) was purchased from Guilin Qihong Technology Co., Ltd, China (purity $>99 \mathrm{wt} \%$, diameter 4-10 nm, length 1-3 $\mu \mathrm{m}$ ). Waterborne epoxy (WEP, product number F0704) and curing agent (product number F0705) were purchased from Shenzhen Jitian Chemical Co., Ltd, China. The materials were all used as received. Deionized (DI) water was prepared in our lab. A horn-type sonicator (JY92, Ningbo Scientz Biotechnology Co., Ltd, China) and a magnetic stirrer (LC-TN-1, LICHEN Instrument, China) were used to assist the dispersion of RGO.
2.2. Preparation of the RGO-CNF/WEP Composite. Figure 1 shows the fabrication process of the composite. WEP has high viscosity which is not conducive to uniform dispersion of RGO. So, as a first step, WEP is mixed with water, and the mixture is magnetic stirred at a speed of $1000 \mathrm{r} / \mathrm{min}$ for $10 \mathrm{~min}$. This yields an aqueous solution of WEP (S1) with low viscosity. Second step, the RGO and CNF powders are added in DI water, magnetic stirred at a speed of $2000 \mathrm{r} / \mathrm{min}$ for $5 \mathrm{~min}$ and then ultrasonic dispersed at $200 \mathrm{~W}$ for $1 \mathrm{~h}$. Due to less surface group, low chemical activity, and high specific surface area of RGO, agglomeration phenomenon often occurs when RGO is dispersed in water. There are a large number of hydrophilic hydroxyl groups on the surface of CNF, which enable CNF to form stable and uniform suspension in water. Some unreduced hydroxyl and carboxyl groups are distributed on the surface of RGO. They can interact with the hydroxyl groups on the surface of CNF by hydrogen bonding. CNF acted as a template to help RGO disperse in water. Then, RGO-CNF suspension solution (S2) is obtained. CNF, on the one hand, acts as a dispersant for RGO, on the other hand, acts as a framework for supporting RGO, to promote the formation of threedimensional reinforcement and conductive network in polymer matrix. The two prepared solutions, S1 and S2, are mixed in one container with magnetic stirring at a speed of $1000 \mathrm{r} / \mathrm{min}$ for $5 \mathrm{~min}$ and followed ultrasonic dispersion at $200 \mathrm{~W}$ for $3 \mathrm{~h}$. The solution (S3) with RGO-CNF uniformly dispersed in WEP is obtained. Then, a curing agent is added in S3 at a mass ratio of $1: 2$. After 10 min of magnetic stirring at a speed of $1000 \mathrm{r} / \mathrm{min}$, it is placed in the vacuum box for $30 \mathrm{~min}$ to remove bubbles. Subsequently, it is put in the oven to complete curing at $40^{\circ} \mathrm{C}$ for 3 hours and at $60^{\circ} \mathrm{C}$ for 24 hours. The choice of curing temperature is the key to the formation of a stable reinforcement and conductive network. If the temperature is high and the water evaporates too quickly, the network between graphene flakes will be destroyed, thus affecting the mechanical and electrical properties of the composites [24]. Table 1 is the filler percentage of samples, and the values of RGO and CNF are mass percent to WEP. 
TABLE 1: Filler percentage of samples.

\begin{tabular}{lccc}
\hline Sample number & RGO & CNF & WEP \\
\hline WEP & 0 & 0 & 100 \\
A2/0 & 2 & 0 & 100 \\
A4/0 & 4 & 0 & 100 \\
B2/2 & 2 & 2 & 100 \\
B $/ 2$ & 4 & 2 & 100 \\
B6/2 & 6 & 2 & 100 \\
B8/2 & 8 & 2 & 100 \\
B10/2 & 10 & 2 & 100 \\
\hline
\end{tabular}

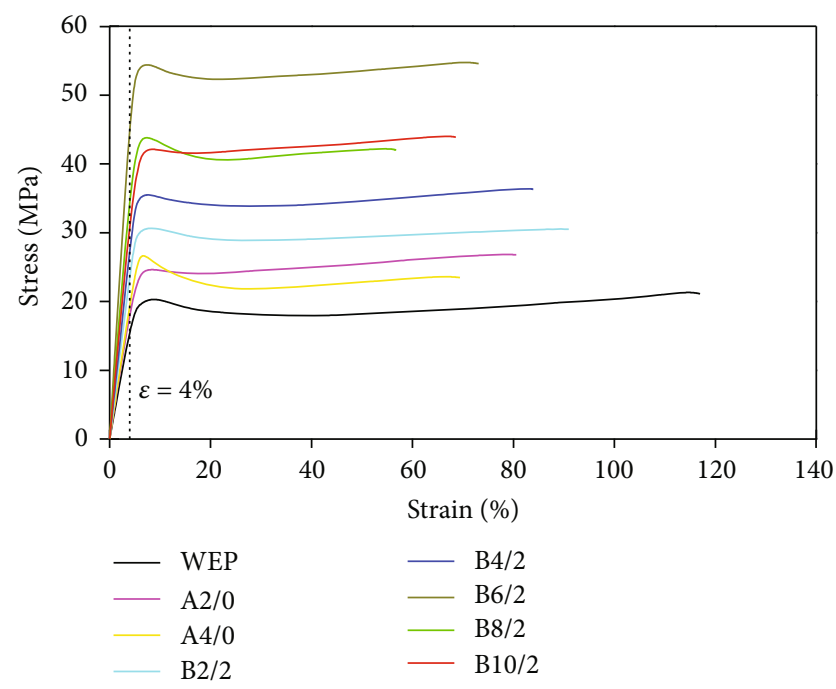

Figure 2: The stress-strain curves of the composites.

2.3. Test Methods of Composite Properties. The mechanical property of the composite was tested using a tensile instrument (HP-500, LANB Instrument, China) at a speed of $1 \mathrm{~mm} / \mathrm{min}$. The electrical resistance of the composite was measured by a 6.5-digit source meter (DMM6500, Keithley Instruments, USA) and the adopted voltage was AC $220 \mathrm{~V}$. Copper foil electrodes were preembedded in the composite during fabrication process, and 2-prode method was used. The composite specimen was cut into a rectangular shape, and the distance between two electrodes was $100 \mathrm{~mm}$. The width of the specimen was $10 \mathrm{~mm}$ and its thickness was $1 \mathrm{~mm}$. At least three effective specimens were tested for each sample.

\section{Properties of the RGO-CNF/WEP Composite}

3.1. Mechanical and Electrical Properties. Figure 2 shows the stress-strain curve of the composites. It shows that the addition of RGO and CNF can significantly improve the tensile strength of epoxy. With the increase of RGO content, the tensile strength of the composites increases firstly and then decreases. The composites are in the elastic deformation stage within $4 \%$ strain range, and stress is proportional to strain. Their elastic moduli are calculated and the results can be seen in Table 2. When the content of RGO and $\mathrm{CNF}$ is $6 \mathrm{wt} \%$ and $2 \mathrm{wt} \%$, respectively, the elastic modulus of the composite reaches the largest value of $12.02 \mathrm{GPa}$, which is in the same magnitude order with the elastic modulus of concrete.

With the help of CNF, the conductive filler RGO is evenly dispersed in epoxy. When the distance between RGO flakes is small enough, the "tunnel effect" occurs, which makes the RGO-CNF/WEP composite becomes electrically conductive. Table 2 shows the conductivity of the composites. The maximum conductivity is $3.4 \times 10^{-1} \mathrm{~S} / \mathrm{m}$, and the content of RGO and CNF is $6 \mathrm{wt} \%$ and $2 \mathrm{wt} \%$, respectively, which corresponds to the filler content of the composite with the maximum elastic modulus.

The improvement of mechanical and electrical properties of the RGO-CNF/WEP composites mainly depends on the binding state of RGO and CNF, the dispersion level of RGO-CNF in WEP, and the combination of RGO-CNF with WEP in micro level. As a green and renewable onedimensional nanomaterial, CNF acts as dispersant and structural skeleton in the composite. RGO combines with CNF through hydrogen bond. The overlapping CNF can carry RGO to disperse evenly in the WEP matrix. It helps form a stable and continuous conductive network of RGO in the WEP matrix. Moreover, owing to the high strength and modulus of RGO and CNF, a cross-linking enhanced network is also constructed in the WEP matrix, which significantly improves the mechanical property of the composite. However, if RGO or CNF is added excessively, CNF could not carry redundant RGO to be uniformly dispersed into the WEP matrix, which destroyed the balance among the three components in the composite. The redundant RGO and CNF agglomerate in the WEP matrix, resulting in stress concentration which would decrease the mechanical property of the composite, meanwhile affecting the electrical property.

\subsection{Electromechanical Properties of the RGO-CNF/WEP} Composite. When the composite material is deformed by external force, the internal conductive network also deforms and the distance between RGO flakes changes, which makes the composite resistance change. Figure 3 shows the relative resistance change versus the strain of the RGO-CNF/WEP composite film. It can be seen that except for sample B2/2, the relative resistance change of other films has a good linear relationship with the strain. This was because the electrical network of sample B2/2 was imperfect at low RGO content. The phenomenon of resistance varying with strain belongs to piezoresistive effect. Gauge factor (GF) is usually used to evaluate this property of materials, and it associates resistance change rate with external strain, as shown in equation (1). The slope of fitting line of the curve in Figure 3 equals the GF of the film. The GFs of B4/2-B10/2 are 16-52, which are all obviously larger than the GF of traditional metal strain gauges ( 2). Cycle tensile tests on specimens B6/2 and B10/2 showed good repeatability and GF remained basically unchanged, as shown in Figure 4. The results indicate that 
TABLE 2: Elastic modulus and conductivity of samples.

\begin{tabular}{lcccccccc}
\hline Sample number & A2/0 & A4/0 & B2/2 & B4/2 & B6/2 & B8/2 & B10/2 & WEP \\
\hline Elastic modulus $(\mathrm{GPa})$ & 4.74 & 4.98 & 6.13 & 6.91 & 12.02 & 9.39 & 8.26 & 4.07 \\
Conductivity $(\mathrm{S} / \mathrm{m})$ & $6.2 \times 10^{-8}$ & $2.7 \times 10^{-5}$ & $2.1 \times 10^{-3}$ & $3.9 \times 10^{-2}$ & $3.4 \times 10^{-1}$ & $9.6 \times 10^{-2}$ & $1.5 \times 10^{-1}$ & Nonconductive \\
\hline
\end{tabular}

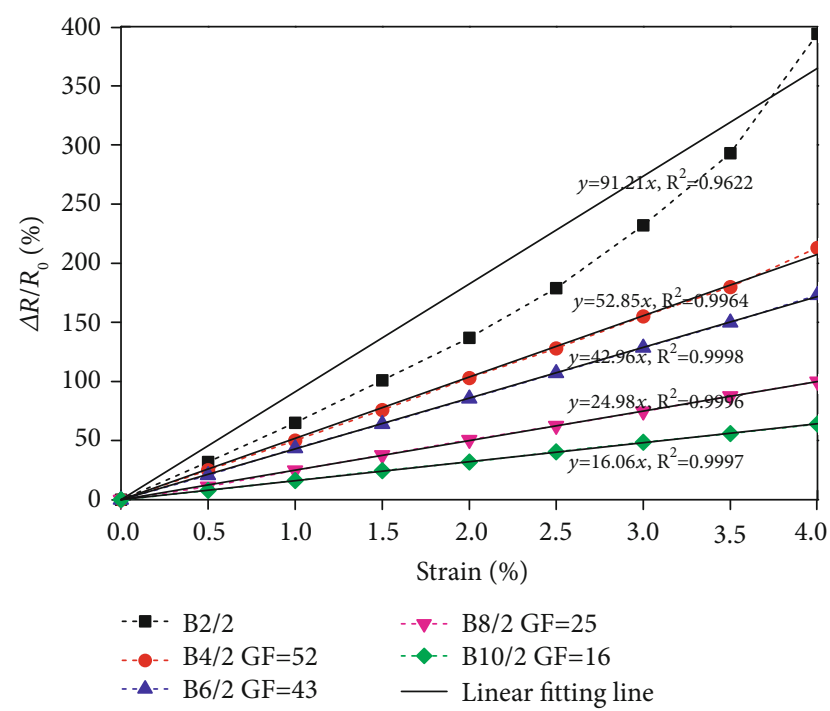

FIGURE 3: The relative resistance change versus the strain of the RGO-CNF/WEP composite films.

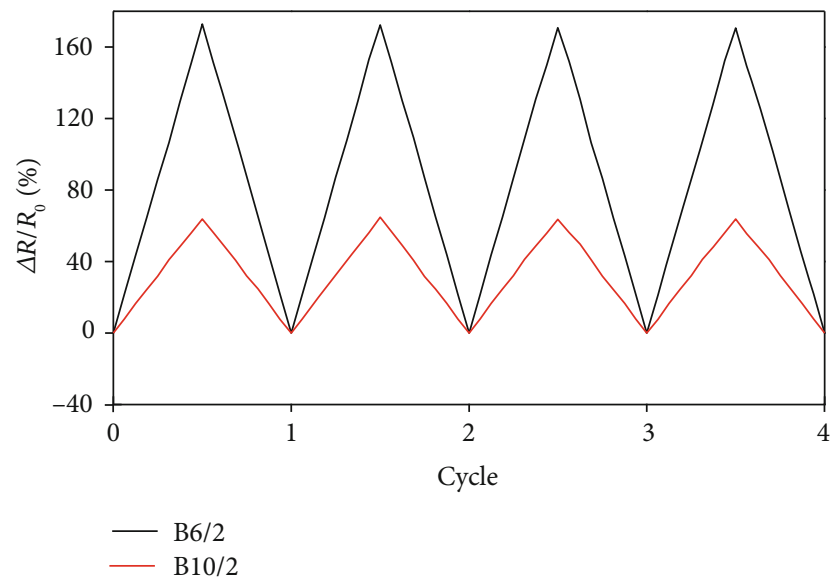

Figure 4: Cycle test of the RGO-CNF/WEP composite films.

the RGO-CNF/WEP composite has good strain sensing property and can be used to structural health monitoring.

$$
\mathrm{GF}=\frac{\Delta R / R_{0}}{\varepsilon}
$$

where $\Delta R$ is the relative resistance change and $R_{0}$ is the initial resistance of the composite film.
Strain sensor is widely used in structural damage detection and health monitoring. The traditional resistance strain sensor is mainly fabricated by metal or semiconductor materials. They have some defects such as small range, poor toughness, and easy to damage, which are unable to meet the needs in complex structures and large strain monitoring. From the above results, it can be seen that the films made of the RGO-CNF/WEP composite have good strain sensing performance with high sensitivity, good stability, and large measurement range. And the excellent mechanical property and corrosion resistance of epoxy can protect the film from environmental impact. In addition, it also has well plasticity to be made into the desired shape. Therefore, the RGO$\mathrm{CNF} / \mathrm{WEP}$ composite can be made into film strain gauges instead of metal or semiconductor strain gauges, which can be used to measure the strain on the surface of concrete structures. Film strain gauges with different GF can be obtained by adjusting the filler content of the composite to the needs of individual application, for example, high GF for low-strain applications and low GF for high deformation applications [25].

However, there is still a lack of effective means to measure the internal strain state of concrete. At present, most of the researches are to bury smart cement or polymer blocks into the structure and can only obtain strain data in a single direction. However, the internal stress state of concrete structure is complex, and it is difficult to get accurate results from onedimensional sensors. Therefore, it is necessary to develop a new sensor which can measure 3D strain.

\section{Principle and Design of a 3D Strain Rosette}

4.1. Principle of a 3D Strain Rosette. The strain of a point in concrete under 3D state can be described by three normal strains and three shear strains, as shown in Figure 5. If the strain state of point $A$ in Figure $5(\mathrm{~b})$ is $\left(\varepsilon_{x}, \varepsilon_{y}, \varepsilon_{z}, \gamma_{x y}\right.$, $\left.\gamma_{y z}, \gamma_{z x}\right)$, according to the strain theory, the linear strain $\varepsilon$ in any direction through point $A$ can be expressed as [26-28]

$$
\begin{aligned}
\varepsilon & =\varepsilon_{x} l^{2}+\varepsilon_{y} m^{2}+\varepsilon_{z} n^{2}+\gamma_{x y} l m+\gamma_{y z} m n+\gamma_{z x} n l, \\
l & =\sin \delta \cos \varphi \\
m & =\sin \delta \sin \varphi \\
n & =\cos \delta
\end{aligned}
$$

where $l, m$, and $n$ are directional cosines of line $A B$ on $x$-, $y$-, and $z$-axes, respectively, $\delta$ is the angle between line $A B$ and $z$-axis, and $\varphi$ is the angle between $x$-axis and the projection of line $A B$ on planar $x A y$. 


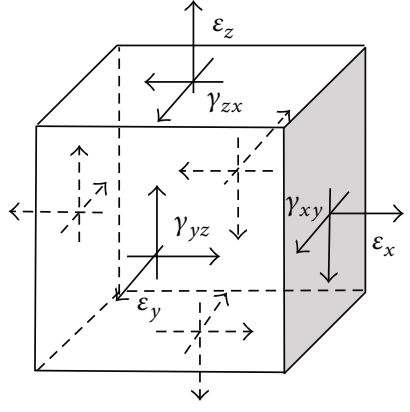

(a)

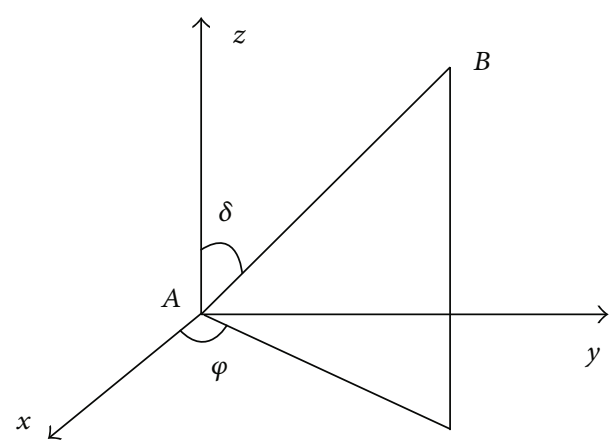

(b)

FIgURE 5: The strain of a point under three-dimensional state.

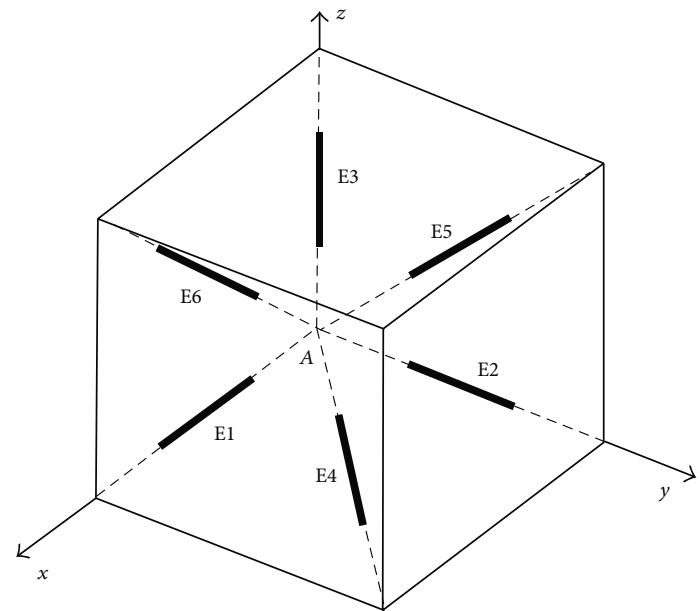

FIGURE 6: The structure of a 3D strain rosette.

For the selected direction, $\delta$ and $\varphi$ are known quantities, then $l, m$, and $n$ can be obtained by equations (3)-(5). Therefore, for equation (2), in order to solve the six unknown variables $\left(\varepsilon_{x}, \varepsilon_{y}, \varepsilon_{z}, \gamma_{x y}, \gamma_{z x}, \gamma_{y z}\right)$, at least six different linear strains at this point need to be known. In theory, there can be multiple layouts for several strain gauges to form a $3 \mathrm{D}$ strain rosette. Figure 6 shows the structure of a sample 3D strain rosette. E1-E6 are six sensing elements (SE) through point $A$.

If the strains of E1-E6 are $\varepsilon_{i}(i=1,2,3,4,5,6)$, the following can be obtained from equation (2):

$$
\left\{\begin{array}{l}
\varepsilon_{1} \\
\varepsilon_{2} \\
\varepsilon_{3} \\
\varepsilon_{4} \\
\varepsilon_{5} \\
\varepsilon_{6}
\end{array}\right\}=\left[\begin{array}{llllll}
l_{1}^{2} & m_{1}^{2} & n_{1}^{2} & l_{1} m_{1} & m_{1} n_{1} & n_{1} l_{1} \\
l_{2}^{2} & m_{2}^{2} & n_{2}^{2} & l_{2} m_{2} & m_{2} n_{2} & n_{2} l_{2} \\
l_{3}^{2} & m_{3}^{2} & n_{3}^{2} & l_{3} m_{3} & m_{3} n_{3} & n_{3} l_{3} \\
l_{4}^{2} & m_{4}^{2} & n_{4}^{2} & l_{4} m_{4} & m_{4} n_{4} & n_{4} l_{4} \\
l_{5}^{2} & m_{5}^{2} & n_{5}^{2} & l_{5} m_{5} & m_{5} n_{5} & n_{5} l_{5} \\
l_{6}^{2} & m_{6}^{2} & n_{6}^{2} & l_{6} m_{6} & m_{6} n_{6} & n_{6} l_{6}
\end{array}\right]\left\{\begin{array}{c}
\varepsilon_{x} \\
\varepsilon_{y} \\
\varepsilon_{z} \\
\gamma_{x y} \\
\gamma_{y z} \\
\gamma_{z x}
\end{array}\right\} .
$$

TABLE 3: The directional cosines of the six sensing elements.

\begin{tabular}{lccccc}
\hline Sensing element & $\delta$ & $\varphi$ & $l$ & $m$ & $n$ \\
\hline E1 & 90 & 0 & 1 & 0 & 0 \\
E2 & 90 & 90 & 0 & 1 & 0 \\
E3 & 0 & 0 & 0 & 0 & 1 \\
E4 & 90 & 45 & 0.707 & 0.707 & 0 \\
E5 & 45 & 90 & 0 & 0.707 & 0.707 \\
E6 & 45 & 0 & 0.707 & 0 & 0.707 \\
\hline
\end{tabular}

Setting

$$
[K]=\left[\begin{array}{cccccc}
l_{1}^{2} & m_{1}^{2} & n_{1}^{2} & l_{1} m_{1} & m_{1} n_{1} & n_{1} l_{1} \\
l_{2}^{2} & m_{2}^{2} & n_{2}^{2} & l_{2} m_{2} & m_{2} n_{2} & n_{2} l_{2} \\
l_{3}^{2} & m_{3}^{2} & n_{3}^{2} & l_{3} m_{3} & m_{3} n_{3} & n_{3} l_{3} \\
l_{4}^{2} & m_{4}^{2} & n_{4}^{2} & l_{4} m_{4} & m_{4} n_{4} & n_{4} l_{4} \\
l_{5}^{2} & m_{5}^{2} & n_{5}^{2} & l_{5} m_{5} & m_{5} n_{5} & n_{5} l_{5} \\
l_{6}^{2} & m_{6}^{2} & n_{6}^{2} & l_{6} m_{6} & m_{6} n_{6} & n_{6} l_{6}
\end{array}\right]
$$

then

$$
\left\{\varepsilon_{i}\right\}=[K]\left\{\varepsilon_{j}\right\}
$$

where $\left\{\varepsilon_{i}\right\}=\left\{\varepsilon_{1}, \varepsilon_{2}, \varepsilon_{3}, \varepsilon_{4}, \varepsilon_{5}, \varepsilon_{6}\right\}^{T},\left\{\varepsilon_{j}\right\}=\left\{\varepsilon_{x}, \varepsilon_{y}, \varepsilon_{z}, \gamma_{x y}, \gamma_{y z}\right.$, $\left.\gamma_{z x}\right\}^{T}$

Table 3 is the directional cosines of the six sensing elements in Figure 6. From equation (7), it can be obtained as follows:

$$
[K]=\left[\begin{array}{cccccc}
1 & 0 & 0 & 0 & 0 & 0 \\
0 & 1 & 0 & 0 & 0 & 0 \\
0 & 0 & 1 & 0 & 0 & 0 \\
0.5 & 0.5 & 0 & 0.5 & 0 & 0 \\
0 & 0.5 & 0.5 & 0 & 0.5 & 0 \\
0.5 & 0 & 0.5 & 0 & 0 & 0.5
\end{array}\right] .
$$




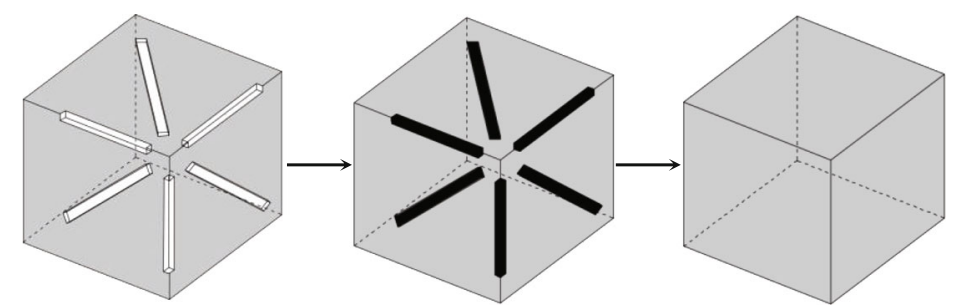

Forming cube with grooves

Forming sensing elements

Coating protective layer

(a)

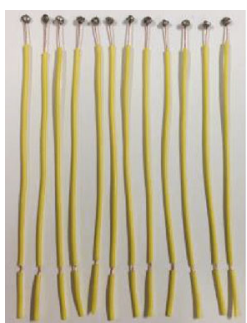

Electrodes

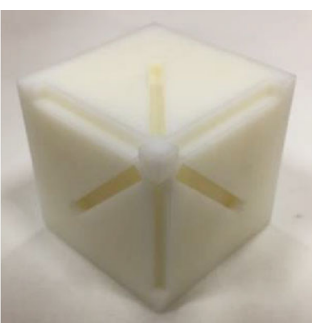

Cube with grooves

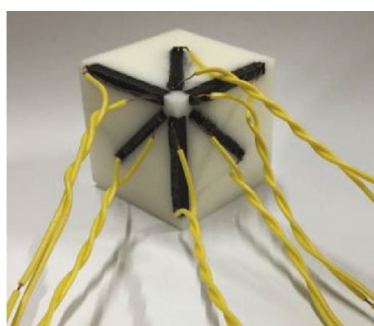

Cube with sensing elements

(b)

Figure 7: Fabrication of the 3D strain rosette sensor. (a) Fabrication process. (b) Some components.

Then

$$
\left\{\varepsilon_{j}\right\}=[K]^{-1}\left\{\varepsilon_{i}\right\}
$$

4.2. Design and Fabrication of a 3D Strain Rosette. A 3D strain rosette sensor based on the RGO-CNF/WEP composite was fabricated. Figure 7 shows the fabrication process of the $3 \mathrm{D}$ strain rosette sensor. Using the good plasticity of WEP, six grooves were reserved as the layout of Figure 6 when forming a WEP cube with the size of $40 \mathrm{~mm} \times 40 \mathrm{~mm} \times 40 \mathrm{~mm}$. The grooves were formed by strong magnetic strips attracted at the designed location of the mould. The size of the grooves is $30 \mathrm{~mm} \times 3 \mathrm{~mm}$ $\times 3 \mathrm{~mm}$. Then, the RGO-CNF/WEP composite was filled in the grooves. After the composite curing, six sensing elements were formed. The composite can be well joint with the WEP cube which ensures sensing elements and cube to deform together. At last, a WEP layer of about $1 \mathrm{~mm}$ thick was coated on the surface of the cube. The epoxy protective layer has good corrosion resistance and waterproof performance, which can prevent the damage of the internal sensing elements. It avoids the influence of external environment on the sensor and ensures the stability of the sensor performance.

4.3. Error Analysis. The total error of the sensor includes systematic error and random error. The errors that existed before the measurement, which will always affect the accuracy of the measurement results inevitability, are systematic errors, for example, the errors caused by the angle deviation between the sensing elements of the threedimensional strain gauge. If the systematic error of each

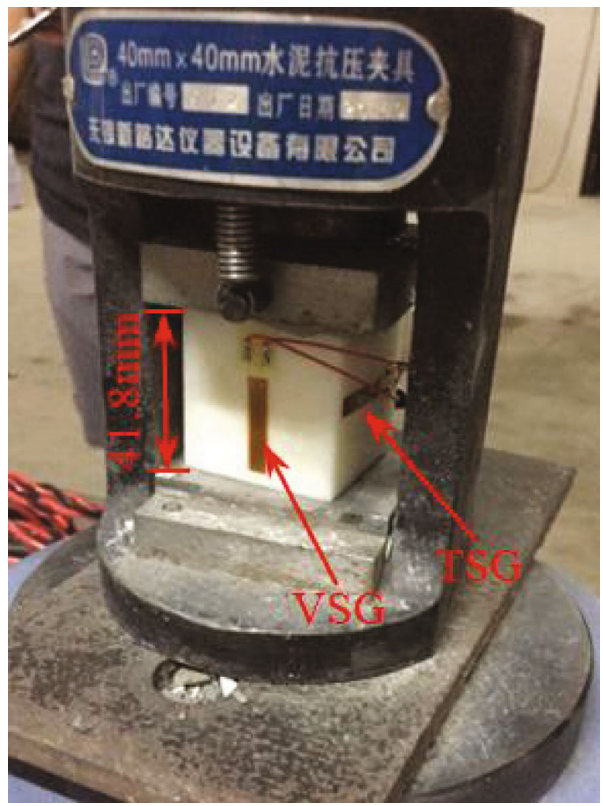

FIgURE 8: Test of the 3D strain rosette sensor.

sensing element is $\Delta \varepsilon_{i}$, the systematic error of strain component can be obtained as follows:

$$
\Delta \varepsilon_{j}=\sum_{i=1}^{6} k_{j i} \Delta \varepsilon_{i},
$$

where $k_{j i}$ is the value of the matrix $[K]^{-1}$ at row $j$ and column $i$. 


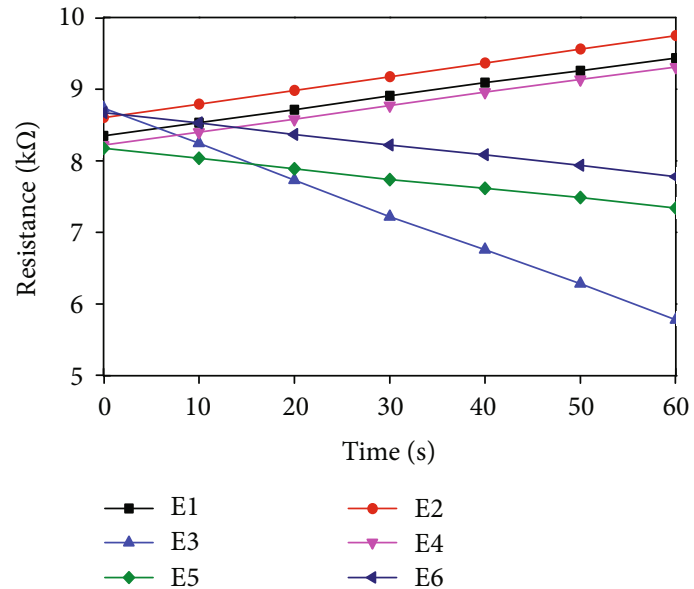

(a)

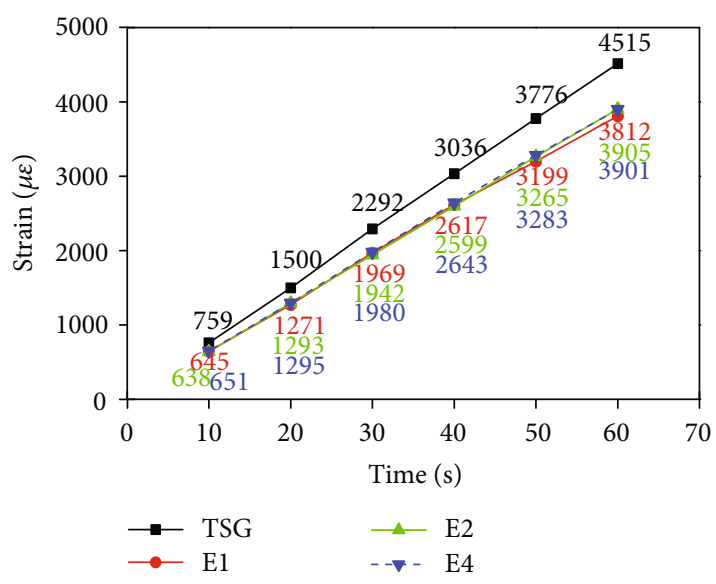

(c)

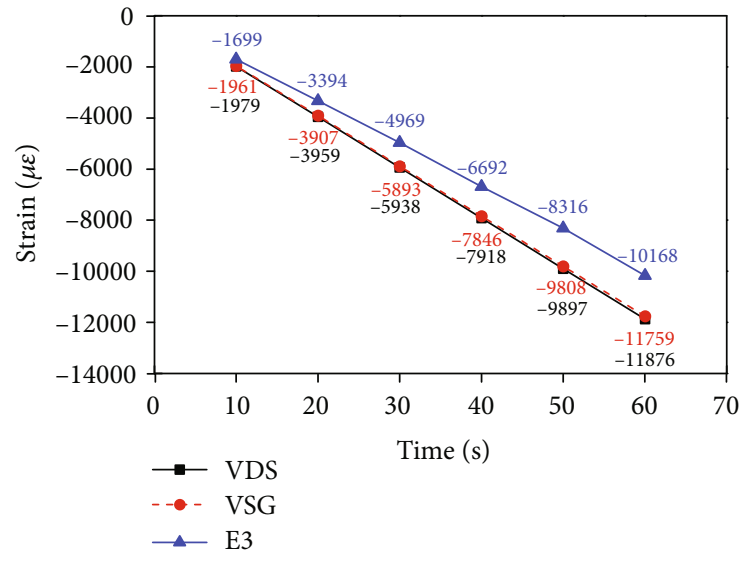

(b)

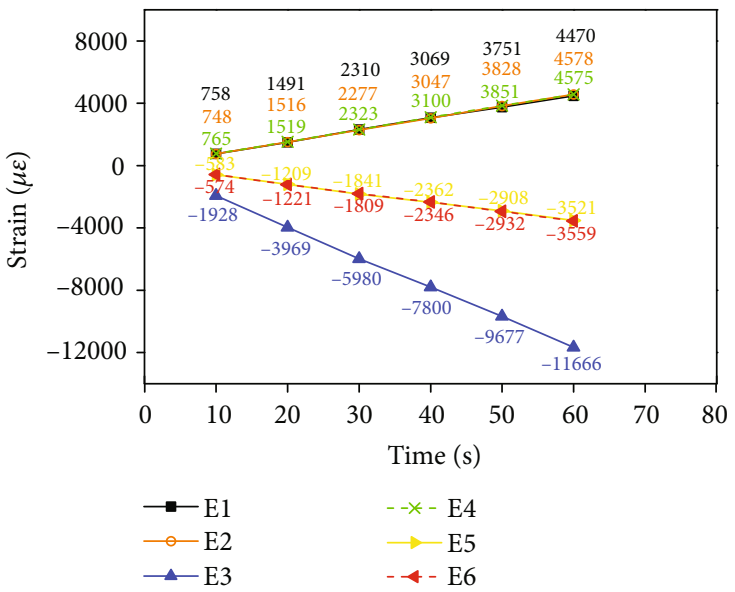

(d)

FIGURE 9: Resistances and strains of SEs and strain gauges. (a) Resistances of SEs. (b) Vertical strains. (c) Transverse strains. (d) Strains of SEs.

TABLE 4: Slope of fitting line of strain.

\begin{tabular}{lcccc}
\hline Slope & Vertical strain & \multicolumn{3}{c}{ Transverse strain } \\
\hline SL1 & $167.73(\mathrm{E} 3)$ & $64.2(\mathrm{E} 1)$ & $65.05(\mathrm{E} 2)$ & $65.47(\mathrm{E} 4)$ \\
SL2 & $196.08(\mathrm{VSG})$ & \multicolumn{3}{c}{$75.56(\mathrm{TSG})$} \\
SL1/SL2 & 0.86 & 0.85 & 0.86 & 0.87 \\
& & 0.86 (average value) & \\
\hline
\end{tabular}

When repeated measurements of the same sensor are carried out with equal precision, a series of different results are obtained, and the deviations with actual value are random errors. If the random error of each sensing element is $R\left(\varepsilon_{i}\right)$, the random error of strain component can be obtained as follows:

$$
R\left(\varepsilon_{j}\right) \leq R\left(\varepsilon_{i}\right) \sqrt{\sum_{i=1}^{6} k_{j i}^{2}} .
$$

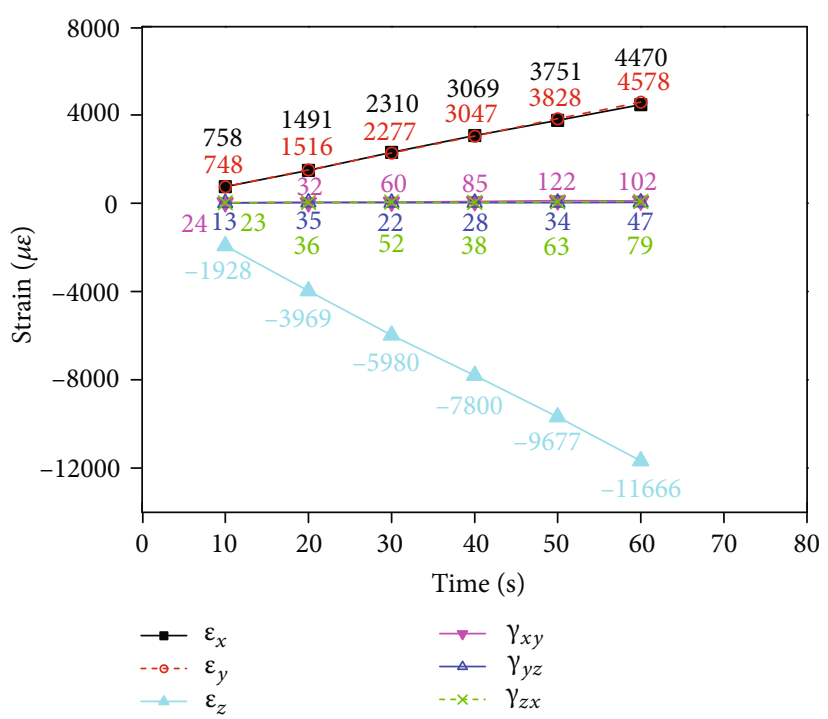

FIgURE 10: Three-dimensional strain state of point $A$. 


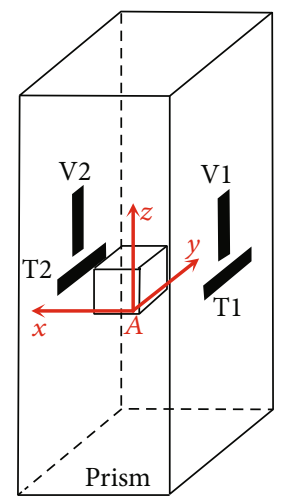

(a)

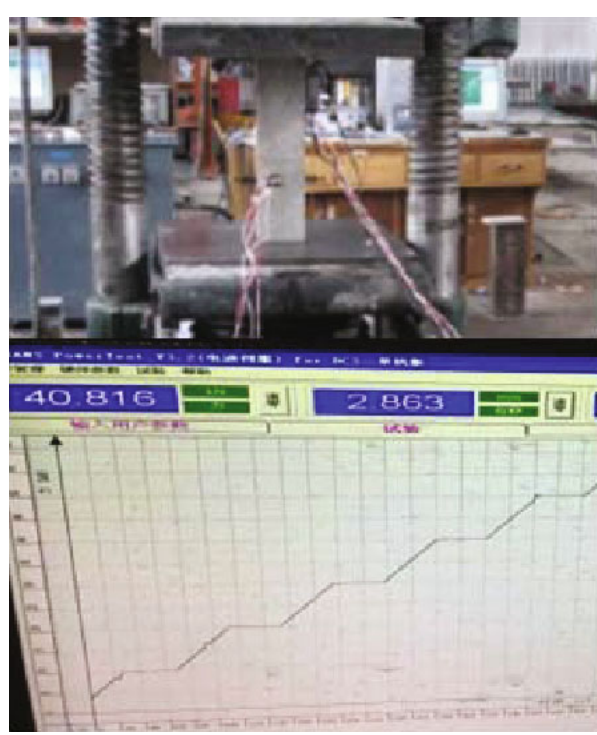

(b)

FIgURE 11: Sensor arrangement and load test. (a) Sensor arrangement. (b) Load test.

\section{Performance Testing and Analysis of the 3D Strain Rosette Sensor}

5.1. Test of the 3D Strain Rosette. Because of the good linearity and high sensitivity of the B6/2 RGO-CNF/WEP composite, it was selected to fabricate SEs of the 3D strain rosette sensor. As shown in Figure 8, the performance of the prepared sensor was tested. Axial pressure was applied by a pressure testing machine (TYA-300B, Wuxi Xinluda Instrument Equipment, China), and the loading speed was $0.5 \mathrm{~mm} / \mathrm{min}$. Two PTFE films were placed on the upper and lower surfaces of the machine to reduce friction between the sensor and the machine. The resistances of SEs were measured by the DMM6500 source meter. A vertical strain gauge (VSG) and a transverse strain gauge (TSG) were attached to one side of the sensor, and a static resistance strain indicator (JM3841, Yangzhou Jingming Technology Co., Ltd, China) was used to measure vertical and transverse strains of VSG and TSG. During the loading process, displacement, resistance, and strain were collected synchronously every 10 seconds for a total of 60 seconds. The coordinate system of the strain rosette is set as shown in Figure 6.

Figure 9(a) shows the resistance of SEs over time. The initial resistances of SEs vary slightly due to the difference in fabrication. GF of sample B6/2 is 34 , and the strain of E3 can be obtained according to equation (1), as shown in Figure 9(b). The vertical displacement of the sensor was the same as that of the instrument. Then, the displacement was transformed into strain (VDS), and its change over time was shown in Figure 9(b). The strain of VSG was also shown in Figure 9(b). As can be seen in Figure 9(b), the line of VSG and VDS almost coincide, while the line of E3 deviates from them but has the same trend. It can be inferred that the strain of VSG approximates to the true vertical strain, while the strain of E3 needs to be modified. The strains of E1, E2, and E4 transformed from their resistances by equation (1)

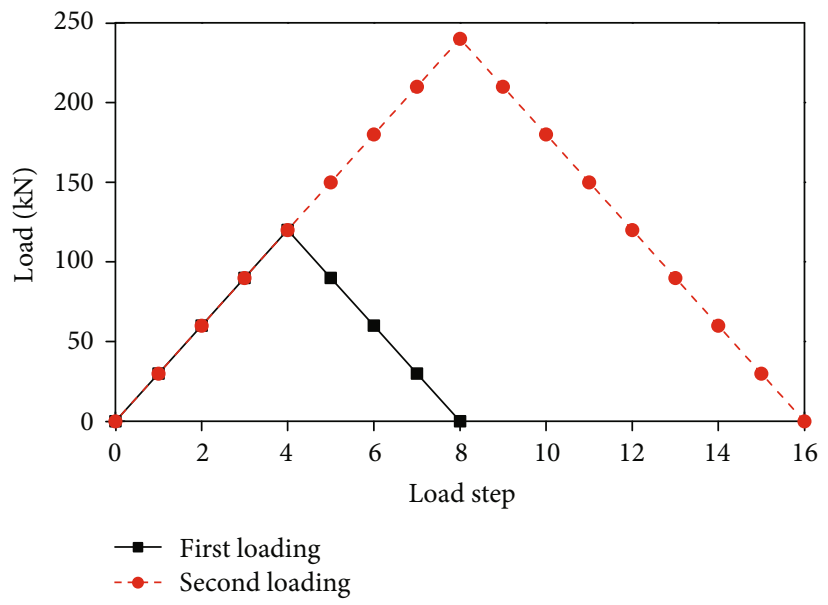

FIGURE 12: Loading history.

were shown in Figure 9(c). The strain of TSG was also shown in Figure 9(c). They all represent the transverse strain of the sensor. The strains of E1, E2, and E4 are close, but they have deviations from the strain of TSG. It is similar to the analysis of vertical strain. The difference between the measured strains of SEs and strain gauges is mainly caused by the GF value which is used to calculate strain from resistance. It is because that GF of the composite is shape-dependent. The length-thickness ratio of SEs is different with that of the tested specimens. So $\mathrm{GF}_{c}=34$ is not the true value $\left(\mathrm{GF}_{t}\right)$ of SEs. According to equation (1), the ratio of calculated strain $\left(\varepsilon_{c}\right)$ to true strain $\left(\varepsilon_{t}\right)$ is as follows:

$$
\begin{aligned}
\frac{\varepsilon_{c}}{\varepsilon_{t}} & =\frac{\left(\Delta R / R_{0}\right) / \mathrm{GF}_{c}}{\left(\Delta R / R_{0}\right) / \mathrm{GF}_{t}}, \\
\mathrm{GF}_{t} & =\frac{\varepsilon_{c}}{\varepsilon_{t}} \cdot \mathrm{GF}_{c} .
\end{aligned}
$$




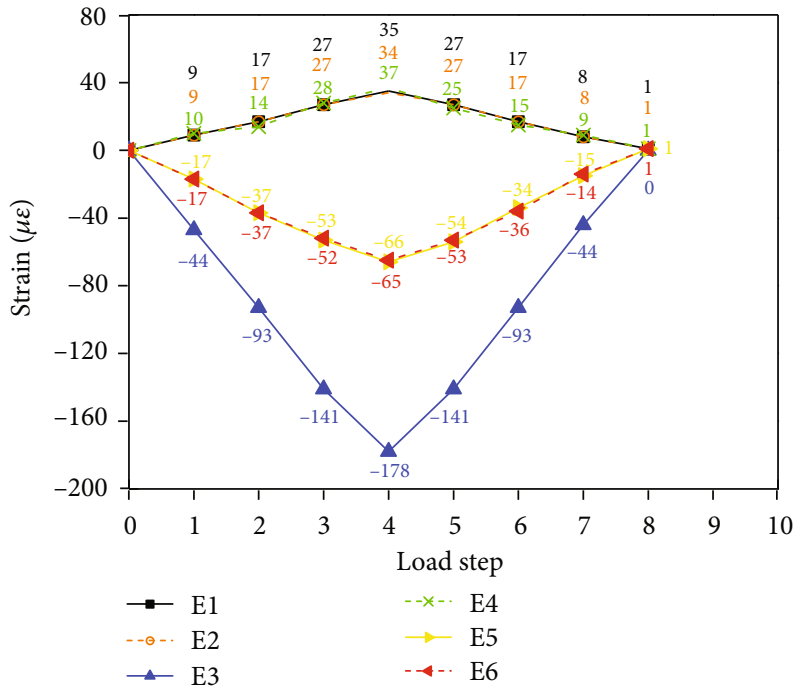

(a)

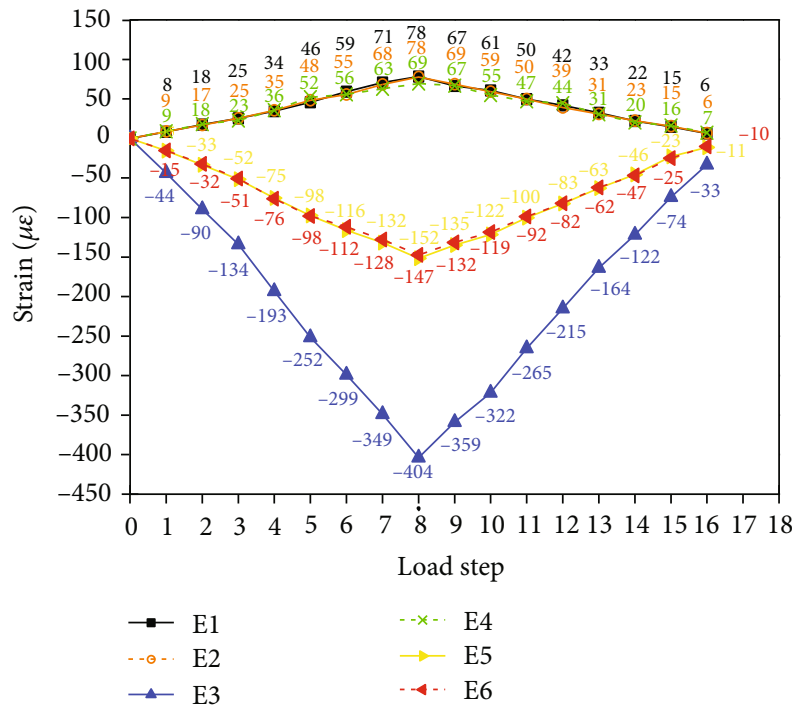

(c)

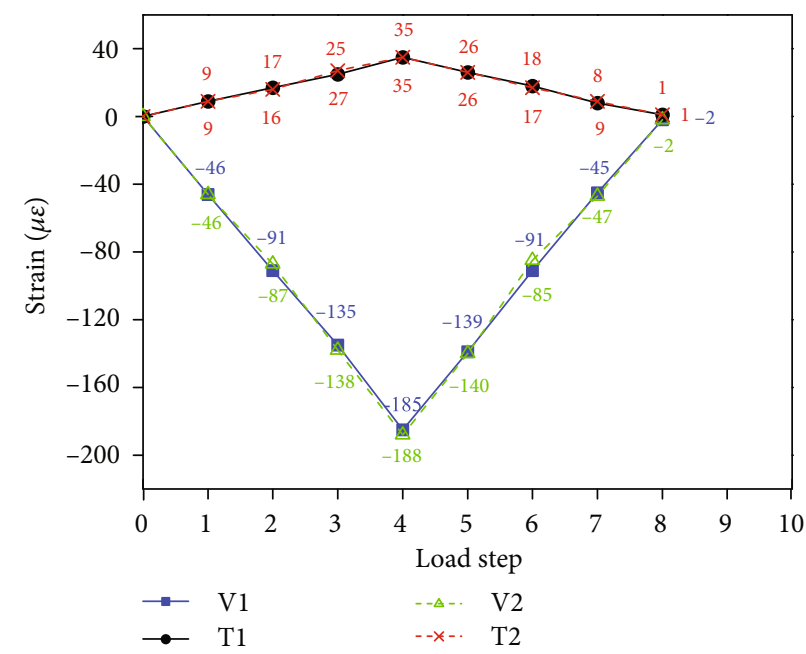

(b)

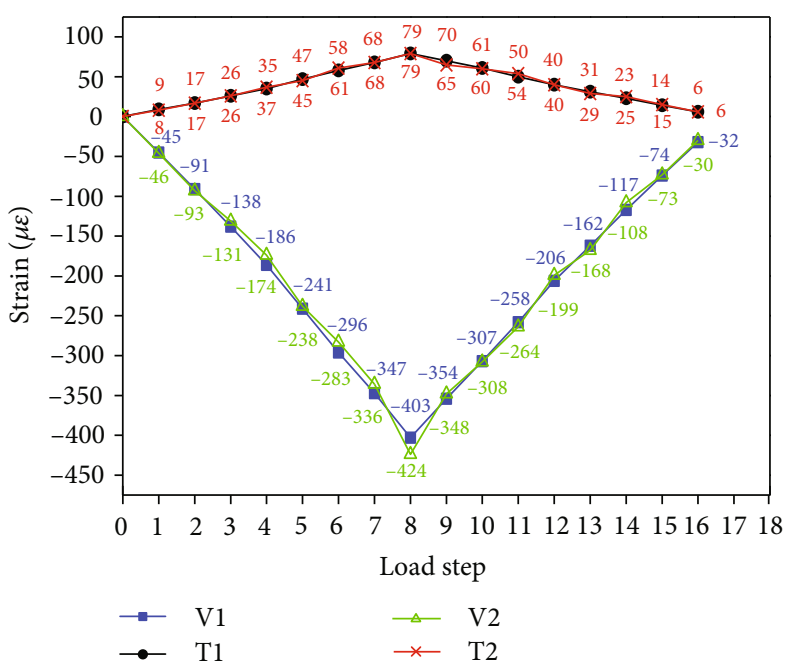

(d)

FIGURE 13: Measured strains of the 3D strain rosette and strain gauges. (a) Strains of rosette at first loading. (b) Strains of V1, T1, V2, and T2 at first loading. (c) Strains of rosette at second loading. (d) Strains of V1, T1, V2, and T2 at second loading.

The strains of VSG and TSG can be considered as true strains, and their values can be used to modify the GF of SEs. In Figures $8(\mathrm{~b})$ and 8 (c), the strains of VSG, TSG, and SEs almost change linearly, and Table 4 shows the slope of the fitting line of the corresponding data. According to equation (14), $\mathrm{GF}_{t}=0.86 \times 34=29$. In addition, it can be seen from the table that the ratio of TSG to VSG is 0.385 , which is consistent with Poisson's ratio of the WEP matrix (0.39, provided by the material company).

Figure 9(d) shows the strain of SEs calculated using the modified $\mathrm{GF}_{t}$. Figure 10 shows the $3 \mathrm{D}$ strain state of point $A$ calculated from the strain of SEs according to equation (10). It can be seen that the vertical and transverse strains of point $A$ coincide with those of VSG and TSG, and its shear strains are very small, relatively. The measured $3 \mathrm{D}$ strain state of point $A$ is consistent with its actual strain state, which verifies the correctness and feasibility of the $3 \mathrm{D}$ strain rosette sensor.

5.2. Test of the 3D Strain Rosette Embedded in Concrete. To test the performance of the $3 \mathrm{D}$ strain rosette in concrete strain monitoring, a prism with a size of $150 \mathrm{~mm} \times 150 \mathrm{~mm}$ $\times 500 \mathrm{~mm}$ was poured using C30 concrete (standard value of axial compressive strength $f_{\mathrm{ck}}=20.1 \mathrm{MPa}$ ). The 3D strain rosette was embedded in the prism, and its surface was polished so that it can bond well with the concrete. After standard curing, a loading test was performed on the prism by a pressure testing machine (WAW-600, Shanghai Hualong Testing Instrument, China). A vertical strain gauge (V1) and a transverse strain gauge (T1) were pasted on one 


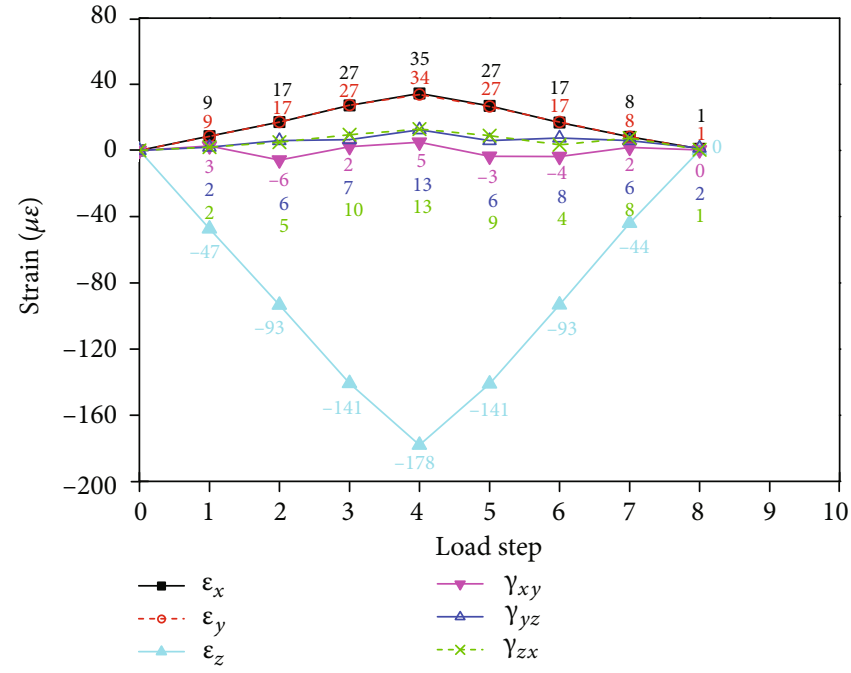

(a)

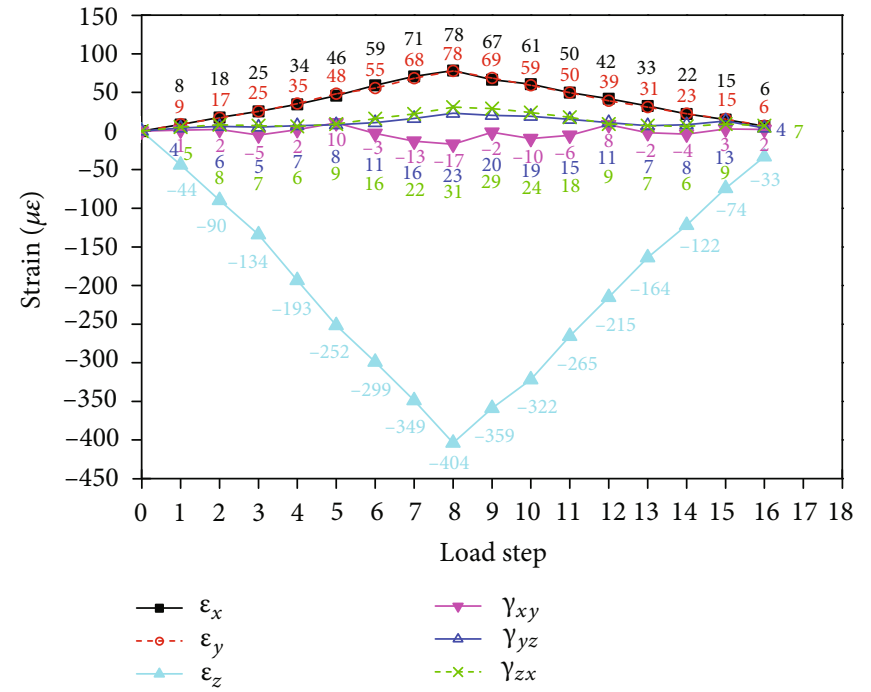

(b)

Figure 14: 3D strain state of point $A$. (a) First loading. (b) Second loading.

side of the prism. A vertical strip film (V2) and a transverse strip film (T2) made of the B6/2 composite were applied on the opposite side. The sensor arrangement and load test are shown in Figure 11. The axial pressure was applied step by step and unloaded step by step after reaching the predetermined value. Two times of loading were carried out. Figure 12 shows the loading history. The JM3841 static resistance strain indicator was used to measure the strains of the $3 \mathrm{D}$ strain rosette and strain gauges. The modified $\mathrm{GF}_{t}=29$ was used for the $3 \mathrm{D}$ strain rosette.

Figures 13(a) and 13(c) show the strains of SEs of the 3D strain rosette. Figures 13(b) and 13(d) show the strains of V1, T1, V2, and T2. During the two loading processes, for longitudinal strain, the strain of E3 is close to that of L1, while for transverse strain, the strains of E1, E2, and E4 are close to that of T1. This indicates that there is a good bond between SEs and the WEP matrix and between the 3D strain rosette and the concrete. So they can deform synchronously.

According to equation (2), the 3D strain state of point $A$ in concrete can be obtained, which is shown in Figure 14. It can be seen that the three normal strains are close to the corresponding strains of $\mathrm{L} 1$ and $\mathrm{T} 1$, and the three shear strains are small, which is consistent with the actual strain state of point $A$. But there are also some tiny differences, which may be caused by the following reasons: (i) Concrete is not a fully homogeneous material, so the stress transfer is not completely uniform. (ii) There are errors in manufacturing, such as deviations in the angle and size between SEs. There may also be deflection in the placed angle of the strain rosette. (iii) Poisson's ratio of the matrix material (0.39) of the strain rosette is different from that of the concrete (0.19). This will result in a difference in deformation of SE when the strain rosette is embedded in concrete or not. However, because of the large slenderness ratio of SE, the deformation of the width direction of SE has little effect on the deformation of the length direction.
From the two loading processes, the stress of the first loading is small, the concrete is in the stage of elastic deformation, the stress-strain relationship is close to a straight line, and the strain almost recovers to zero after unloading; the stress of the second loading is larger, the microcracks expand, and there is plastic strain after unloading. This is consistent with the measured results of the 3D strain rosette, which shows that the $3 \mathrm{D}$ strain rosette can be used to measure the internal strain of concrete. In addition, the strains of L1 and T1 are close to the strains of L2 and T2, respectively. It indicates that the composite film can also be used to measure the surface strain of concrete.

\section{Conclusions}

Modified polymer material with piezoresistive effect can be used to prepare new sensors for concrete structural health monitoring. Based on strain theory, a 3D strain rosette sensor was designed and fabricated using the RGO-CNF/WEP composites to obtain the strains in concrete structures. Firstly, the composite was prepared using RGO as the conductive filler, $\mathrm{CNF}$ as the dispersant and structural skeleton, and WEP as the polymer matrix. Then, a WEP cube was formed and six grooves were reserved in its six different directions. Subsequently, the RGO-CNF/WEP composite was filled in grooves to form six one-dimensional sensing elements. At last, a protective layer was coated on the cube surface and the 3D strain rosette was finished. Nanomaterials RGO and CNF with high strength and modulus form a stable and continuous threedimensional reinforcing and conductive network in the WEP matrix, which significantly improves the mechanical and electrical properties of the composite. The GFs of the composites are 16-52, which are larger than the GF of traditional metal strain gauges. Within $4 \%$ strain, the sensing performance of the composites is stable with good linearity and repeatability. The 3D strain rosette was tested, and the 
measured strains are close to the actual strain state of measure point. The RGO-CNF/WEP composite has excellent mechanical and piezoresistive properties, which enable the fabricated 3D strain rosette to be used as an embedded sensor to measure the internal strain of concrete structures accurately. Moreover, the composite with good plasticity also can be made into film sensors to replace the traditional metal or semiconductor strain gauges for strain measurement on concrete surface.

\section{Data Availability}

The data used to support the findings of this study are included within the article.

\section{Conflicts of Interest}

The authors declare that there are no conflicts of interest regarding the publication of this paper.

\section{Acknowledgments}

The work was funded by the National Natural Science Foundation of China (Project Nos. 51778628 and 51578547).

\section{References}

[1] J. L. Humar and M. S. Amin, "Structural health monitoring," Structural Engineering Mechanics \& Computation, vol. 6531, no. 8, pp. 1185-1193, 2001.

[2] J. M. Ko and Y. Q. Ni, "Technology developments in structural health monitoring of large-scale bridges," Engineering structures, vol. 27, no. 12, pp. 1715-1725, 2005.

[3] Y. Du, B. Sun, J. Li, and W. Zhang, "Cable Stress Monitoring Technology Based on Fiber Bragg Grating," in Optical Fiber Sensing and Structural Health Monitoring Technology, pp. 249-269, Springer, Singapore, 2019.

[4] D. Kinet, P. Mégret, K. W. Goossen, L. Qiu, D. Heider, and C. Caucheteur, "Fiber Bragg grating sensors toward structural health monitoring in composite materials: challenges and solutions," Sensors, vol. 14, no. 4, pp. 7394-7419, 2014.

[5] B. Dong, Y. Liu, L. Qin et al., "In-situ structural health monitoring of a reinforced concrete frame embedded with cement-based piezoelectric smart composites," Research in Nondestructive Evaluation, vol. 27, no. 4, pp. 216-229, 2016.

[6] M. Sun, Q. Liu, Z. Li, and Y. Hu, "A study of piezoelectric properties of carbon fiber reinforced concrete and plain cement paste during dynamic loading," Cement and Concrete Research, vol. 30, no. 10, pp. 1593-1595, 2000.

[7] S. Makireddi and K. Balasubramaniam, "A 1-3 piezoelectric fiber reinforced carbon nanotube composite sensor for crack monitoring," Journal of The Institution of Engineers (India): Series C, vol. 97, no. 3, pp. 345-356, 2016.

[8] H. Shifeng, X. Dongyu, C. Jun, X. Ronghua, L. Lingchao, and C. Xin, "Smart properties of carbon fiber reinforced cementbased composites," Journal of Composite Materials, vol. 41, no. 1, pp. 125-131, 2007.

[9] B. Han, X. Yu, K. Zhang, E. Kwon, and J. Ou, "Sensing properties of cnt-filled cement-based stress sensors," Journal of Civil Structural Health Monitoring, vol. 1, no. 1-2, pp. 17-24, 2011.
[10] L. Zhang, S. Ding, L. Li et al., "Effect of characteristics of assembly unit of $\mathrm{cnt} / \mathrm{ncb}$ composite fillers on properties of smart cement-based materials," Composites Part A: Applied Science and Manufacturing, vol. 109, pp. 303-320, 2018.

[11] K. Loamrat, M. Sappakittipakorn, and P. Sukontasukkul, "Application of cement-based sensor on compressive strain monitoring in concrete members," Advanced Materials Research, vol. 931-932, pp. 446-450, 2014.

[12] J. Olivera, M. González, J. Fuente, R. Varga, A. Zhukov, and J. Anaya, "An embedded stress sensor for concrete shm based on amorphous ferromagnetic microwires," Sensors, vol. 14, no. 11, pp. 19963-19978, 2014.

[13] M. Schulz, Y. Song, A. Hehr, and V. Shanov, "Embedded carbon nanotube thread piezoresistive strain sensor performance," Sensor Review, vol. 34, no. 2, pp. 209-219, 2014.

[14] F. Ubertini, A. L. Materazzi, A. D’Alessandro, and S. Laflamme, "Natural frequencies identification of a reinforced concrete beam using carbon nanotube cement-based sensors," Engineering Structures, vol. 60, pp. 265-275, 2014.

[15] I. Kang, M. J. Schulz, J. H. Kim, V. Shanov, and D. Shi, "A carbon nanotube strain sensor for structural health monitoring," Smart Materials and Structures, vol. 15, no. 3, pp. 737-748, 2006.

[16] A. R. Burton, J. P. Lynch, M. Kurata, and K. H. Law, "Fully integrated carbon nanotube composite thin film strain sensors on flexible substrates for structural health monitoring," Smart Materials and Structures, vol. 26, no. 9, p. 095052, 2017.

[17] J. Herrmann, K. H. Müller, T. Reda et al., "Nanoparticle films as sensitive strain gauges," Applied Physics Letters, vol. 91, no. 18, p. 183105, 2007.

[18] T. Yamada, Y. Hayamizu, Y. Yamamoto et al., "A stretchable carbon nanotube strain sensor for human-motion detection," Nature Nanotechnology, vol. 6, no. 5, pp. 296-301, 2011.

[19] X. Xiao, L. Yuan, J. Zhong et al., "High-strain sensors based on $\mathrm{ZnO}$ nanowire/polystyrene hybridized flexible films," Advanced Materials, vol. 23, no. 45, pp. 5440-5444, 2011.

[20] Z. Jing, Z. Guang-Yu, and S. Dong-Xia, "Review of graphenebased strain sensors," Chinese Physics B, vol. 22, no. 5, 2013.

[21] X. Ji, H. Li, D. Hui, K. T. Hsiao, J. Ou, and A. K. T. Lau, "_I -V_ characteristics and electro-mechanical response of different carbon black/epoxy composites," Composites Part B: Engineering, vol. 41, no. 1, pp. 25-32, 2010.

[22] K. S. Kim, Y. Zhao, H. Jang et al., "Large-scale pattern growth of graphene films for stretchable transparent electrodes," Nature, vol. 457, no. 7230, pp. 706-710, 2009.

[23] H. P. S. A. Khalil, A. H. Bhat, and A. F. I. Yusra, "Green composites from sustainable cellulose nanofibrils: a review," Carbohydrate Polymers, vol. 87, no. 2, pp. 963-979, 2012.

[24] Z. Wu, J. Wei, R. Dong, and H. Chen, "Epoxy composites with reduced graphene oxide-cellulose nanofiber hybrid filler and their application in concrete strain and crack monitoring," Sensors, vol. 19, no. 18, p. 3963, 2019.

[25] Y. Liu, D. Zhang, K. Wang, Y. Liu, and Y. Shang, "A novel strain sensor based on graphene composite films with layered structure," Composites Part A: Applied Science and Manufacturing, vol. 80, pp. 95-103, 2016.

[26] W. E. Baker and R. C. Dove, "Construction and evaluation of a three-dimensional strain rosette," Experimental Mechanics, vol. 3, no. 9, pp. 201-206, 1963. 
[27] S. Rossetto, A. Bray, and R. Levi, "Three-dimensional strain rosettes: pattern selection and performance evaluation," Experimental Mechanics, vol. 15, no. 10, pp. 375-381, 1975.

[28] E. G. Little, D. Tocher, D. Colgan, and P. O'Donnell, “An Analysis of the Factors Influencing the Data Derived from a Plug Type Three-Dimensional Strain Rosette under Compression and Torsion," Strain, vol. 41, no. 4, pp. 193-202, 2005. 


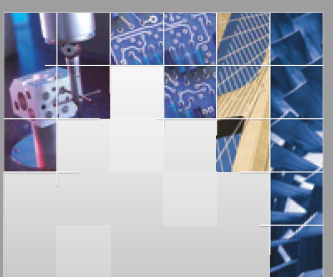

\section{Enfincering}
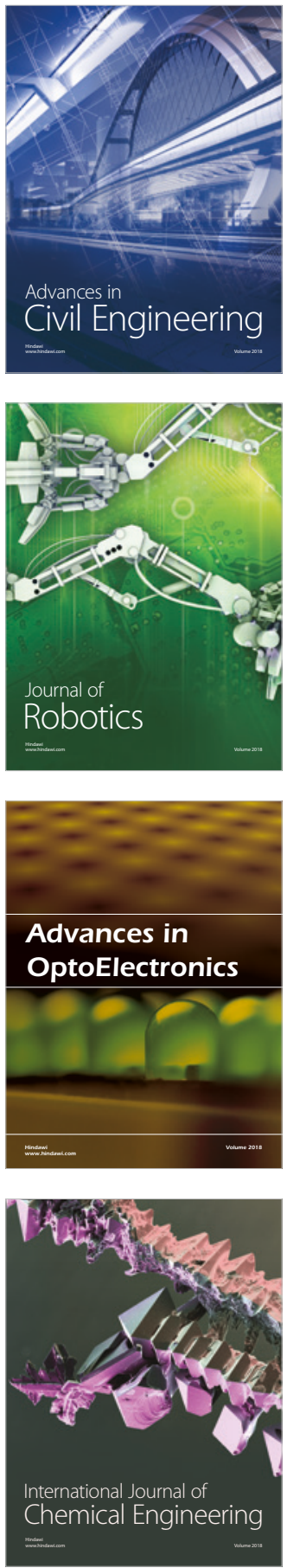

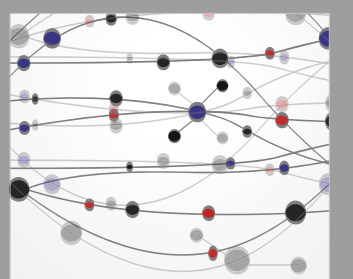

\section{Rotating \\ Machinery}

The Scientific World Journal

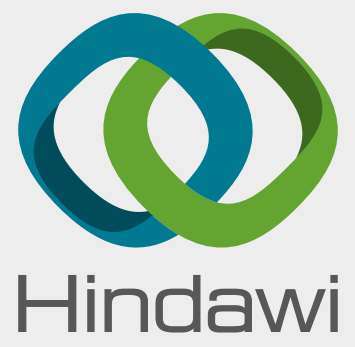

Submit your manuscripts at

www.hindawi.com
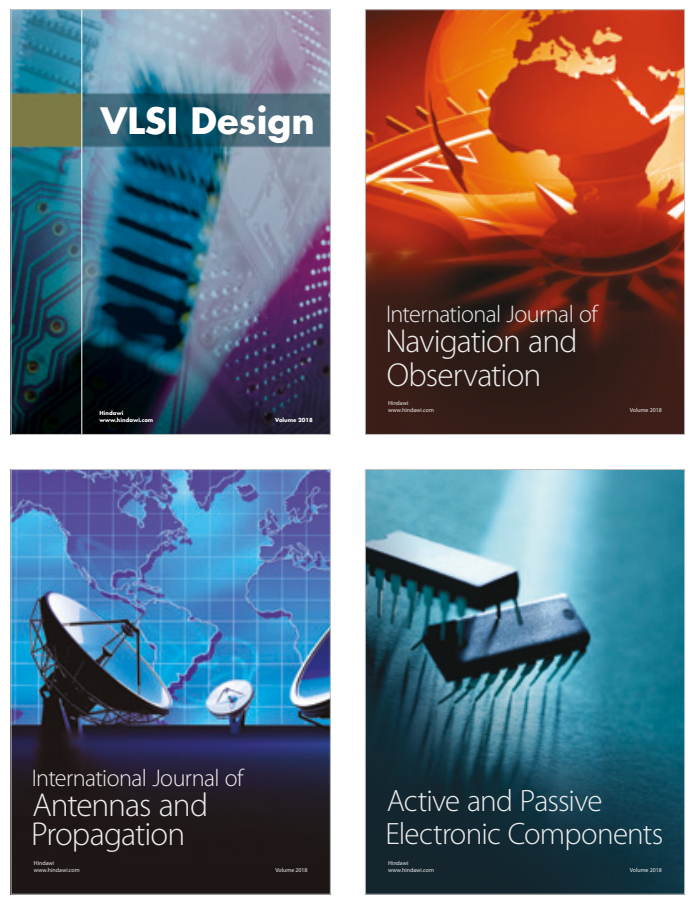
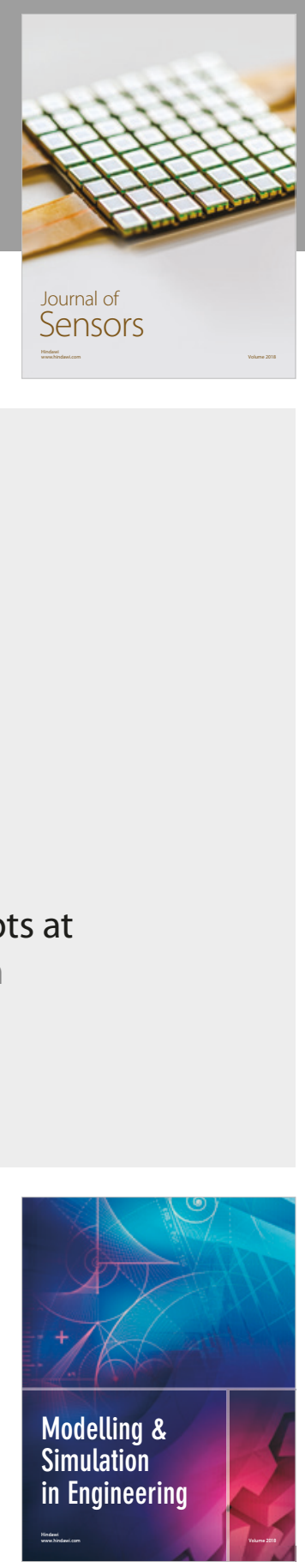

\section{Advances \\ Multimedia}
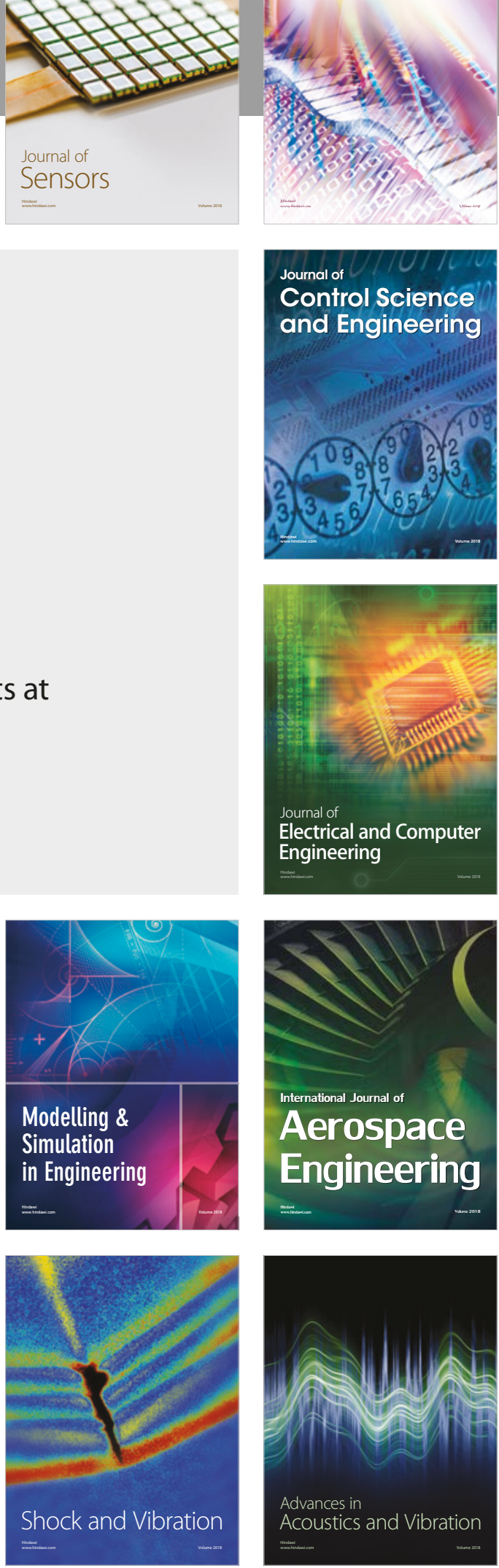